\title{
BOOK NOTICES.
}

An Inductive Chemistry, by Robert H. Bradbury, Ph.D., Head of the Department of Science, Southern High School, Philadelphia. D. Appleton $\&$ Co., New York and Chicago.

Among the great number of text-books which are now available for the teaching of chemistry in our secondary schools this is undoubtedly one of the best. While it may be questioned whether certain innovations the author makes in the arrangement and order of the topics, and in the development of the theory, will appeal to every teacher, we know of no other text that so thoroughly covers elementary chemistry, either as an end in itself or as a preparation for colleges and professional schools. Every paragraph gives evidence not only of the author's mastery of the subject, but also of his long teaching experience. Considering the size of the book, it is very remarkable what an amount of accurate and up-to-date information in all branches of chemistry-inorganic, physical, organic, and industrial-may be found between its covers; and all this matter is thoroughly assimilated in the clear and logical exposition. The book is printed in clear type on good paper; the illustrations by the author's wife are clear and very numerous. A series of fine portraits of the great chemists forms an attractive feature of the book.

HARRY F. KELLER.

Regulation, Valuation and Defreciation of Public Utilities, by Samuel S. Wyer, Mech. and Cons. Engineer. Sears \& Simpson Company, Columbus, Ohio, IgI3. Thin paper, 3I4 pp., gilt edged, flexible leather binding. Price, $\$ 5$, postpaid.

A compendium of technical, economic, and legal data relating to the regulation of public utilities, including a concise presentation of the principles on which the various regulations are based, and brief discussions of the practical application of these principles. The technical phases of the subject are illustrated by a series of graphical and pictorial representations, the economic data by numerous analytical diagrams, all very carefully prepared and unusually well executed. The legal questions are elucidated by brief citations of authoritative opinion, the various discussions being furthermore clarified by references to a long list of technical publications and citations of judicial opinions by the U. S. Supreme Court, the several U. S. Circuit Courts, the Interstate Commerce Commission, various State courts and public service commissions, and by the British Court of Chancery. A copious index completes the thoroughness of this altogether valuable compilation.

L. E. LEVY.

Chemical German, by Francis C. Phillips. Easton, Pa., The Chemical Publishing Company, 19r3. 24I pages ( $44 \times 22 \mathrm{~cm}$.). Price, $\$ 2$.

Most courses in chemistry and chemical engineering require German for admission and include it in their curricula. Nevertheless, graduates of such courses are always unable to read German chemical journals intelligently. 
This is merely another instance of the futile character of the instruction usually given in foreign languages. It is likely that hardly one-hundredth of one per cent. of the students who begin French or German ever get far enough to make any actual use of the language. Probably the chief reason for this state of things is that teachers, for some inexplicable reason, invariably lay the accent on learning to speak the language, instead of learning to read it. The ability to speak a foreign language is a mere showy accomplishment of very little practical value. Further, it is an accomplishment which, without residence in the country where the language is spoken, can be acquired only by a miracle. Finally, if the student should, in some extra-natural way, acquire a fluent speaking knowledge, he would begin to lose it at once through lack of practice, and in a few years the loss would be complete.

However that may be, the inability of young chemists to handle German is a serious matter, since the language is about as important to them as English. Professor Phillips thinks that he has discovered a contributing cause of the difficulty in imperfect specialization in the language teaching His book is an attempt to induct the student into the specific vocabulary of chemical science. There are about fifty pages of introductory exercises. The remainder of the book is occupied by selections from the literature of chemistry and by a vocabulary of chemical terms. The material offered is good, in the main, though naturally very unequal in merit. Some selections, like Victor Meyer's account of his discovery of thiophene, are of first-rate historical importance. On the other hand, the sciolistic characterizations of Berthollet and Scheele from Heller's "Geschichte der Physik" are of value only in so far as they show how completely the historian failed to grasp the significance of the work of these great chemists. There are hardly any technological selections.

All in all, the book is a good one. The student who masters it will be able to read the German journals without much difficulty. Without access to the German literature it is impossible for a chemist to inform himself thoroughly upon any topic.

Robert H. Bradbury.

A New Era in Chemistry. Some of the More Important Developments in General Chemistry during the Last Quarter of a Century. By Harry C. Jones, Professor of Physical Chemistry in Johns Hopkins University. New York: D. Van Nostrand Company, I913. Pp. xii +326 . Price, $\$ 2$. In this book the author has traced very briefly the progress of theoretical chemistry during the past twenty-five years, indicating the chief points of difference between the older and the newer chemistry. Professor Jones's personal acquaintance with many of the pioneers of the "New Era" has enabled him to introduce interesting biographical sketches of these scientists and to enliven his book with some entertaining anecdotes.

After an introductory chapter on the condition of chemistry at the dawn of the "New Era" in 1887 , the author proceeds to outline the development of the law of mass action, the hypotheses of Van't Hoff, Le Bel and Guye, the phase rule of Gibbs, the views of Van't Hoff and Le Chatelier on 